\title{
Motion simulation and test on threshed grains in tapered threshing and transmission device for plot wheat breeding based on CFD-DEM
}

\author{
Fei Dai, Xuefeng Song, Wuyun Zhao*, Zhengsheng Han, Fengwei Zhang, Shilin Zhang \\ (College of Mechanical and Electrical Engineering, Gansu Agricultural University, Lanzhou 730070, China)
}

\begin{abstract}
Mechanization of field experiments is the only way to improve crop breeding and seed propagation effects. In order to further clarify and improve the working performance of tapered threshing device for plot breeding, and reduce the remaining seeds in the device, the numerical simulation was carried out on the motion process of materials in the longitudinal-axial tapered cylinder threshing and transmission device of the plot wheat breeding combine harvester based on CFD-DEM method. Simulation results showed that, threshing and transmission of particles and short stalks at axial direction could be realized under the influence of air flow. Meanwhile, the material transference and distribution rule and stream field distribution rule of air flow in the threshing and transmission device were obtained, the variations of velocity and displacement of particles and short stalks with time were obtained; the motion trajectories and forms of particles in different types of retention were also studied. At rotating speed of 1300-1600 r/min for the tapered threshing cylinder in the verification test, the particle retention rate in the enclosure was $0-0.13 \%$, while in the simulation the particle retention rate in the enclosure was $0-0.11 \%$, only a $0.02 \%$ difference between them. The results proved a favorable feasibility to simulate the working performance of the tapered threshing and transmission device for plot breeding through gas-solid coupling method.
\end{abstract}

Keywords: particle threshing and transmission, tapered threshing and transmission device, hydromechanics calculation, discrete element, numerical simulation, test

DOI: $10.25165 /$ j.ijabe.20191201.4458

Citation: Dai F, Song X F, Zhao W Y, Han Z S, Zhang F W, Zhang S L. Motion simulation and test on threshed grains in tapered threshing and transmission device for plot wheat breeding based on CFD-DEM. Int J Agric \& Biol Eng, 2019; 12(1): $66-73$.

\section{Introduction}

Breeding industry is a chief means to increase grain production and safeguard national food security. In order to enhance the efficiency and quality of crop breeding, mechanized plot breeding should be developed, since mechanized seed industry serves as an important basis and prerequisite for the modernization of seed industry ${ }^{[1]}$. Precision and mechanized plot seed harvesting is the key stage for obtaining correct results in breeding experiments ${ }^{[2,3]}$. However, different from field harvesting, plot breeding harvesting should satisfy the requirements in field harvesting operation as well as ensure special structural requirements of no seed retention, no mixing, and convenient for cleaning. Therefore, mechanized harvesting of plot field breeding is still a difficult question to be solved.

Studies in foreign countries in plot seed harvesting machinery started relatively early, and their developed prototype possessed stable working performance and mature technology, represented by

Received date: 2018-06-08 Accepted date: 2018-11-19

Biographies: Fei Dai, Associate Professor, research interest: design of agricultural mechanization equipment, Email: daifei@gsau.edu.cn; Xuefeng Song, Master candidate, research interest: agricultural mechanization engineering, Email: 549349477@ qq.com; Zhengsheng Han, PhD, Professor, research interest: design of agricultural mechanization equipment, Email: hanzhengsheng@ gsau.edu.cn; Fengwei Zhang, PhD, Professor, research interest: agricultural mechanization engineering, Email: zhangfw@gsau.edu.cn; Shilin Zhang, Master candidate, research interest: agricultural mechanization engineering, Email: 619647034@ qq.com.

*Corresponding author: Wuyun Zhao, $\mathrm{PhD}$, Professor, research interests: farm machine and mechanical reliability. College of Mechanical and Electrical Engineering, Gansu Agricultural University, Lanzhou 730070, China. Tel: +86-451-7632472, Email: zhaowy@gsau.edu.cn.
Wintersteiger in Austria, HEGE in Germany and HALDRUP in Denmark $^{[1,2]}$. However, there are great discrepancies between foreign and domestic breeding pilot plots. The area of foreign pilot plots is large with a wide separate zone, therefore, their harvesting machineries are generally large in size, complicated in structure, expensive and difficult to adapt to the real practice in China, whose pilot plots are small with narrow isolation zone ${ }^{[4]}$. The research on the plot seed harvesting machinery in China started late, with less products and relatively immature key technologies, represented mainly by fixed plot seed threshers. The development of a plot seed combine harvester is basically under research and there are no mature products yet.

A threshing and transmission device is the key component of plot breeding harvesting machinery, also the key element that discriminates plot breeding harvesting machinery from field harvesting machinery, since it directly affects the success of seed breeding ${ }^{[5-7]}$. Seed retention within the threshing and transmission device has been the focus and difficulty that has not been completely solved in the research field. At present, seed cleaning in plot breeding harvesters is mainly finished manually or with the aid of special designed cleaning machine. The complicated structure of seed breeding and threshing machines resulted in the problems of seed retention, difficulty in cleaning, seed mixing and low efficiency ${ }^{[8]}$. To address this problem, the numerical simulation of the motion process of particles in the tapered threshing and transmission device of the plot wheat breeding combine harvester was carried out through the CFD-DEM method, aiming to further improve the working performance of the tapered threshing and transmission device and reduce grain retention within the enclosure of the device. The research results are helpful for the improvement of plot wheat breeding harvest equipment. 


\section{Structure and working principle of threshing and transmission device}

\subsection{Structure of threshing and transmission device}

As shown in Figure 1, longitudinal-axial tapered cylinder type threshing and transmission device is an important part of self-developed plot wheat breeding combine harvester (Figure 2). It is the key component that connects the stripping header of the harvester and the cleaning system and can directly influence the working performance of the whole machine ${ }^{[9]}$.

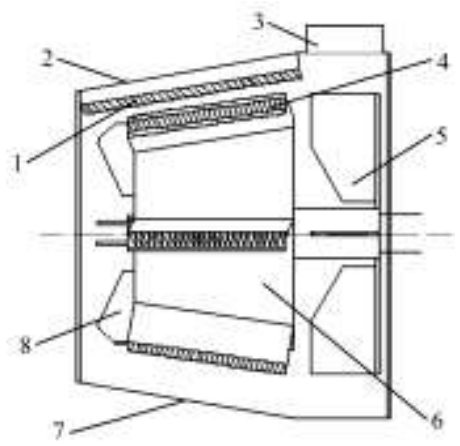

1. Rasp-bar of the upper enclosure 2. Upper enclosure 3. Ascending pipeline 4. L-shaped rasp-bar and plank-tooth threshing element 5. Winnower 6. Tapered threshing cylinder 7 . Lower enclosure 8 . Suction type feeding plate Figure 1 Structure of the longitudinal-axial tapered cylinder type threshing and transmission device

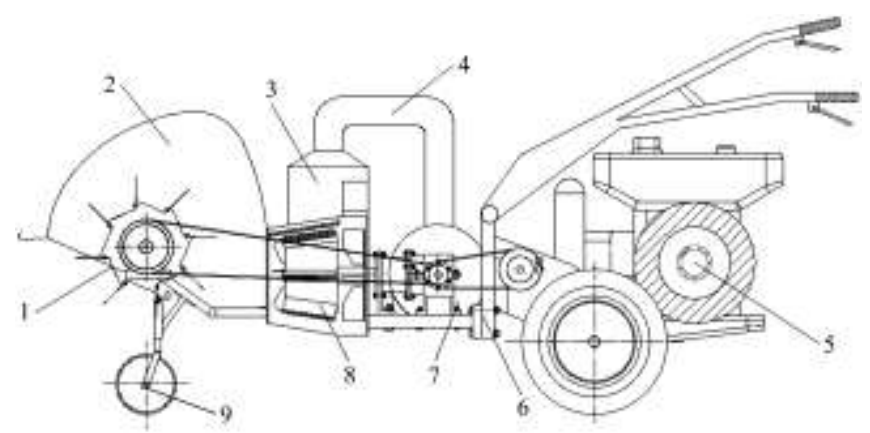

a. Structure

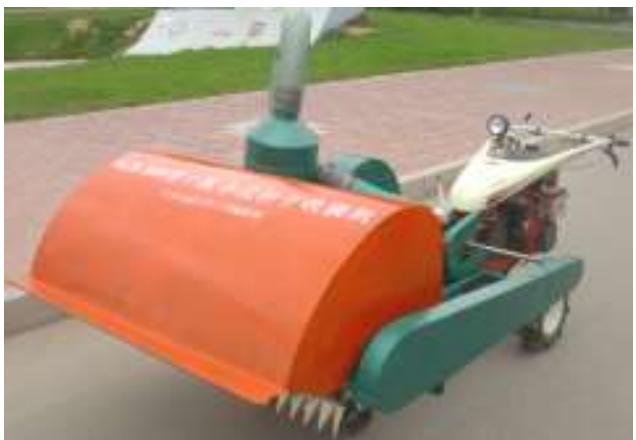

b. Sample machine

1. Stripping header 2. Enclosure 3. Cyclone separator 4. Suction pipeline 5. Power machine 6. Mounting plate 7. Suction fan 8. Longitudinal-axial tapered cylinder threshing and transmission device 9. Supporting wheel

Figure 2 Structure of the plot wheat breeding combine harvester

The longitudinal-axial tapered cylinder threshing and transmission device is mainly composed of suction type feeding plate, L-shaped rasp-bar and plank-tooth threshing cylinder, upper enclosure with rasp-bar threshing element, lower enclosure with smooth inner wall and post winnower. There are 8 groups of threshing elements, the plank-tooth height of $45 \mathrm{~mm}$ and thick of $2 \mathrm{~mm}$, the L-shaped rasp-bar wide of $45 \mathrm{~mm}$ and thick of $6 \mathrm{~mm}$. The surface thread of L-shaped rasp-bar is tilted backward and evenly arranges on the tapered cylinder.

\subsection{Analysis of the working process}

The longitudinal-axial tapered cylinder threshing and transmission device possesses both functions of threshing and whole-process pneumatic conveying of particles. The particles were hit and threshed by the stripping header and suctioned by the suction type feeding plate, and particles enter into the threshing and transmission device, and will be thrown away in radial direction by the centrifugal force from high-speed rotation of the L-shaped rasp-bar and plank-tooth threshing element. Then threshing is completed under the joint action of the rasp-bar on the threshing element and the rasp-bar element on the upper enclosure. The mixture after threshing will be transmitted backwards under the effect of taper angle of the tapered enclosure and air flow in the axial direction, and will be thrown into the cyclone separator through the winnower for cleaning. In the process of material threshing and transmission, the full air transport was adopted to alleviate the retention phenomenon in the machine system. Therefore, in the process of material threshing and transmission, there are effects of airflow field on particle motion, effects of particles on distribution of airflow field distribution, as well as particle-particle, particle-enclosure wall, particle-cylinder surface collisions. There are complicated momentum exchanges between air flow and particles, which is a kind of complicated gas-particle flow. Hence, in order to reduce grain retention in the enclosure, the motion process of particles under the influence of coupled airflow field should be studied.

\section{Force analysis of seed-filling process}

\subsection{Gas governing equation}

Computational fluid dynamics (CFD) is a kind of numerical simulation on fluid controlled by mass conservation equation, momentum conservation equation and energy conservation equation. The simulation process in this study involves the periodic rotation of the tapered cylinder, thus the RNG $k-\varepsilon$ turbulence model was adopted in the numerical simulation ${ }^{[10-12]}$. Compared with the $k-\varepsilon$ model, the RNG $k-\varepsilon$ turbulence model can revise turbulent viscosity and takes into consideration the rotation and swirling flows, thus it can better deal with the problems of high strain-rate and high curvature of streamline and possesses higher credibility and precision in wider range of flow. The equation of RNG $k-\varepsilon$ turbulence model is as follows:

$$
\begin{aligned}
& \frac{\partial \rho \mathrm{k}}{\partial \mathrm{t}}+\frac{\partial}{\partial x_{j}}\left(\rho U_{j} k\right)=-\frac{2}{3} \rho k \frac{\partial u_{k}}{\partial x_{k}}+\frac{\partial}{\partial x_{j}}\left(\frac{\mu_{e f f}}{\sigma_{k}} \frac{\partial k}{\partial x_{j}}\right)+G_{k}-\rho \varepsilon \\
& \frac{\partial \rho \varepsilon}{\partial t}+\frac{\partial}{\partial x_{j}}\left(\rho U_{j} \varepsilon\right)=-\left(\frac{2}{3} C_{\varepsilon 1}-C_{\varepsilon 3}+\frac{2}{3} C_{\mu} C_{\eta} \cdot \frac{k \partial u_{k}}{\varepsilon \partial x_{k}}\right) \cdot \rho \varepsilon \frac{\partial u_{k}}{\partial x_{k}} \\
& +\frac{\partial}{\partial x_{j}}\left(\frac{\mu_{e f f}}{\sigma_{\varepsilon}} \frac{\partial \varepsilon}{\partial x_{j}}\right)+\rho \frac{\varepsilon}{k}\left[\left(C_{\varepsilon 1}-C_{\eta}\right) G_{k}-C_{\varepsilon 2} \rho \varepsilon\right]
\end{aligned}
$$

where, model constants are $C_{\varepsilon 1}=1.42, C_{\varepsilon 2}=1.68$,

$$
\begin{aligned}
& C_{\varepsilon 3}=\left[-1+2 C_{\varepsilon 1}-3 m_{1}(n-1)+(-1)^{\delta} \sqrt{6} C_{\mu} C_{\eta} \eta\right] / 3, \quad \beta=0.015, \\
& C_{\mu}=0.085 \quad, \quad C_{\eta}=\frac{\eta\left(1-\eta / \eta_{0}\right)}{1+\beta \eta^{3}}, \quad \eta=S k / \varepsilon,
\end{aligned}
$$

$S=\sqrt{2 \vec{S}_{i j} \vec{S}_{i j}} \eta_{0}=4.28, \eta$ is ratio of turbulent time scales to mean flow time scales; $S$ is norm of strain rate tensor; the rest are formula constants.

\subsection{Particle contact model}

In this study, the material flow was relatively sparse, thus the plastic deformation of particles caused by collision can be ignored, 
the particle-particle and particle-boundary contact collision are a non-viscous contact with relatively small time steps, the hard-sphere Hertz-Mindlin non-slip contact model was used in other similar studies ${ }^{[13,14]}$. Therefore, this contact model was adopted, as shown in Figure 3.

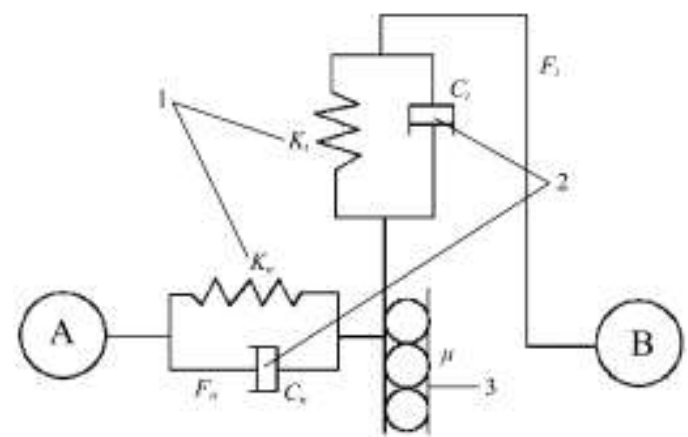

1. Spring stiffness of particles 2. Damper 3. Friction device Note: $F_{n}$ is normal force; $F_{t}$ is tangential force; $k_{n}$ is spring stiffness at normal direction; $k_{t}$ is tangential spring stiffness; $C_{n}$ is damping coefficient at normal direction; $C_{t}$ is tangential damping coefficient; $\mu$ is friction coefficient.

Figure 3 Hertz-Mindlin non-slip contact model

In the theory of discrete element, solid phase can be regarded as discrete element, whose rectilinear motion and rotation conform to newton's second law ${ }^{[15]}$. Solid phase can be expressed by the following equations:

$$
\begin{gathered}
m_{i} \frac{d \overrightarrow{v_{i}}}{d t}=m_{i} \vec{g}+\sum_{j=1}^{k_{i}}\left(\vec{F}_{c, i j}+\vec{F}_{d, i j}\right)+\vec{F}_{p \& f, i}+\vec{F}_{d r a g, i} \\
I_{\mathrm{i}} \frac{d \vec{\omega}_{i}}{d t}=\sum_{j=1}^{k_{i}}\left(\vec{T}_{t, i j}+\vec{T}_{r, i j}\right)
\end{gathered}
$$

where, $m$ is particle weight, $\mathrm{kg} ; \quad \vec{v}_{i}$ is particle velocity, $\mathrm{m} / \mathrm{s} ; \vec{F}_{c, i j}$ is elastic contact force, $\mathrm{N} ; \vec{F}_{d, i j}$ is contact damping force, $\mathrm{N}$; $\overrightarrow{F_{p g f, i}}$ is gradient pressure of flow, $\mathrm{Pa} ; \overrightarrow{F_{d r a g, i}}$ is air drag force, N; $I_{i}$ is rotary inertia of particle in rotation, $\mathrm{kg} \cdot \mathrm{m}^{2} ; \vec{\omega}_{i}$ is angular velocity of particle, $\mathrm{rad} / \mathrm{s} ; \quad \overrightarrow{T_{t, i j}}$ is tangential torque, $\mathrm{N} / \mathrm{m} ; \overrightarrow{T_{r, i j}}$ is rotating friction torque, $\mathrm{N} / \mathrm{m}$.

\section{Model establishment and parameter setting}

\subsection{Model establishment and computing mesh division}

The calculation domain structure of internal flow passage of the tapered threshing and transmission device is relatively complicated and difficult to be obtained; therefore, the geometric model established through Solidworks should be saved as .stp format and imported into the module of ANSYS Workbench Design Modeler. After applying model populating command, the whole calculation domain of internal flow passage was obtained and separated from the cylinder part through Boolean operation, and finally the rotational and static calculation domains were obtained respectively. The rotational calculation domain is composed of two concentric cylinders, which are slightly larger than the cylinder volume. The concentric cylinders are in periodic rotation at working velocity. The interface at contacting face between the dynamic and static calculation domains is established to ensure complete information exchange in the flow field. Figure 4 shows the dynamic and static models for calculation domains of internal flow passage.

In the meshing module, the highly adaptable unstructured tetrahedral mesh was adopted for mesh division, and 320899 meshes were generated in the whole model. Because of the fierce interaction between rotational calculation domain and threshed materials with high air flow velocity and great pressure changes, in order to precisely obtain the value changes in the domain, the meshes were encrypted, and 69195 meshes were obtained finally. Then the mesh model was imported in the FLUENT, after checking, no meshes of negative volume were produced, then MRF (Moving Reference Frame) was adopted for simulation ${ }^{[16]}$.

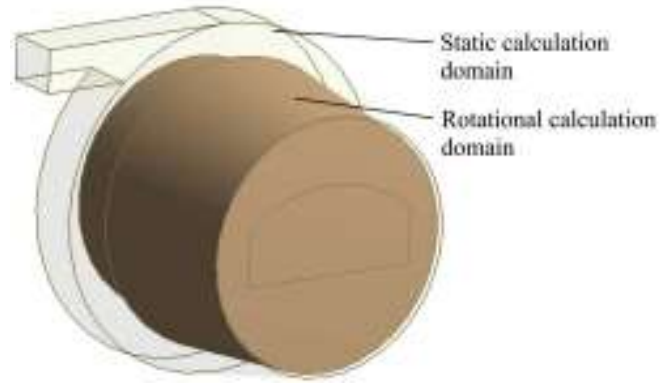

Figure 4 Dynamic and static calculation domains of internal flow passage

\subsection{Material model and parameter setting}

Because of size differences of wheat particles and stalks, in order to reduce the time of simulation calculation, wheat particles with length of $6.6 \mathrm{~mm}$, maximum diameter of $3.6 \mathrm{~mm}$ and wheat stalks with length of $20 \mathrm{~mm}$ and external diameter of $3 \mathrm{~mm}$ were selected as objects in modeling in EDEM, and the model of wheat particles and stalks was established by the multi-sphere aggregation method, as shown in Figure $5^{[10,17]}$.

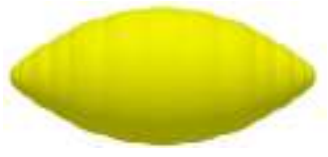

a. Wheat particle model

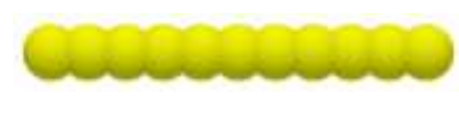

b. Wheat stalk model
Figure 5 Models of threshed materials

The parameters of poisson's ratio, elastic modulus and density of material are very important in the simulation of threshing and transmission process in EDEM, which are shown in Table 1. The recovery coefficients of all materials were set as follows: particle-particle recovery coefficient was 0.2 , particle-stalk recovery coefficient was 0.2 , recovery coefficient between particles and the enclosure wall was 0.5 , the static friction factors of all materials were set as follows: particle-particle static friction factor was 1 , particle-stalk static friction factor was 0.8 , that between particles and the enclosure wall was 0.58 , the dynamic friction factor among all materials was set as $0.01^{[17,18]}$.

Table 1 Setting of the material parameters

\begin{tabular}{clc}
\hline \multicolumn{1}{c}{ Item } & \multicolumn{1}{c}{ Parameter } & Value \\
\hline \multirow{3}{*}{ Particles } & Poisson's ratio & 0.30 \\
& Elastic modulus/Pa & $2.60 \times 10^{6}$ \\
& Density $/ \mathrm{kg} \cdot \mathrm{m}^{-3}$ & 1350 \\
\hline \multirow{2}{*}{ Stalks } & Poisson's ratio & 0.40 \\
& Elastic modulus/Pa & $1.0 \times 10^{6}$ \\
& Density $/ \mathrm{kg} \cdot \mathrm{m}^{-3}$ & 100 \\
\hline \multirow{2}{*}{ Wall surface } & Poisson's ratio & 0.30 \\
& Elastic modulus $/ \mathrm{Pa}$ & $7.0 \times 10^{8}$ \\
& Density $/ \mathrm{kg} \cdot \mathrm{m}^{-3}$ & 7800 \\
\hline
\end{tabular}

After modeling and parameter setting of the materials, the kinetic characteristics and material properties should be analyzed. Based on the actual motion of the tapered cylinder of the threshing and transmission device, the cylinder model is defined as linear 
rotation in EDEM, with rotation axis as its geometric center. The material feeding amount of the cylinder was $0.3 \mathrm{~kg} / \mathrm{s}$. Based on ratio of grain to straw was 100:5 in plot wheat breeding, 7281 wheat grains and 388 stalks were produced per second by the material plant after calculation.

\subsection{Coupling parameter setting of the model}

Matched parameters should be set in the coupling calculation to ensure the stable exchange of gas-solid data. The total volume of materials for threshing and transmission in this study took up less than $10 \%$ of volume of calculation domain. In simulation, the influence of air flow on solid phase materials was mainly taken into consideration, while the influence of solid phase material on air flow was small (can be omitted), therefore, Euler-Lagrange algorithm model was adopted for coupling calculation. In calculation of FLUENT, subject phase was regarded as continuous phase, and sparse phase was regarded as discrete particles. The particle tracing was completed by Eulerian method while dispersed phase was completed by Lagrangian method.

After coupling calculation, firstly, FLUENT let a time step iterate computational convergence, then data was transmitted to EDEM for solid phase calculation of current step. After iteration calculation by EDEM, data was sent to FLUENT solver for calculation of next time step. Gas-solid coupling was completed by interactive exchange between particle's drag force and two-phase momentum exchange. The momentum on each grid cell was transferred to EDEM particles to express the energy influence. Therefore, before producing threshing and transmission by the material plant in EDEM, the calculation of

FLUENT should have convergence of iteration, and the time steps and data retention time should be integral multiples ${ }^{[19]}$. Meanwhile, in order to achieve high calculation precision, the time step in EDEM calculation should be $5 \%-40 \%$ of Rayleigh step ${ }^{[20]}$ to avoid penetration of materials into surface wall of the geometry for high time step. The parameter setting of coupling time steps are listed in Table $2^{[21]}$.

Table 2 Coupling time step parameters

\begin{tabular}{cccc}
\hline Model & Time step/s & Retention frequency/step & Retention time/s \\
\hline FLUENT & $5.0 \times 10^{-4}$ & 50 & 0.10 \\
EDEM & $5.0 \times 10^{-6}$ & 200 & 0.01 \\
Multiples & 100 & - & 10 \\
\hline
\end{tabular}

\section{Simulation process and result analysis}

\subsection{Material transmission rule}

The numerical simulation on the motion process of threshed materials in the enclosure of the device is based on CFD-DEM. The motion process of materials in the longitudinal-axial tapered threshing and transmission device was simulated when the rotating speed of threshing cylinder were at $1300 \mathrm{r} / \mathrm{min}, 1450 \mathrm{r} / \mathrm{min}$ and $1600 \mathrm{r} / \mathrm{min}$ respectively, the inlet air velocity of the tapered threshing and transmission device was $12.5 \mathrm{~m} / \mathrm{s}$, the breeding wheat particles and stalks were produced at initial speed of $0 \mathrm{~m} / \mathrm{s}$. The material transmission process and rule were mainly analyzed through the materials velocity, air velocity and dynamic pressure of the tapered threshing cylinder in the threshing and transmission device, as shown in Figure 6.

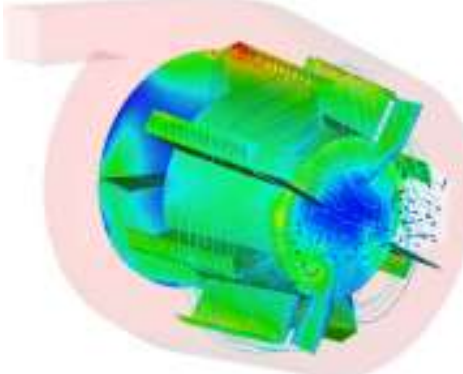

a. $0.01 \mathrm{~s}$

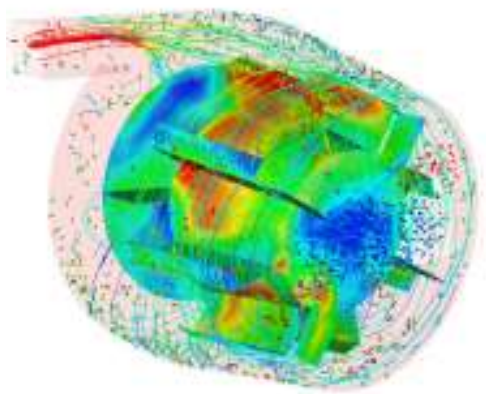

d. $0.25 \mathrm{~s}$

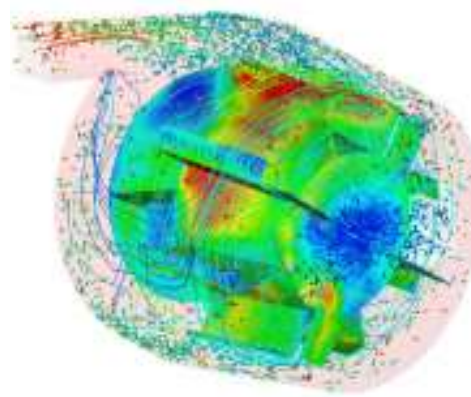

g. $1.50 \mathrm{~s}$

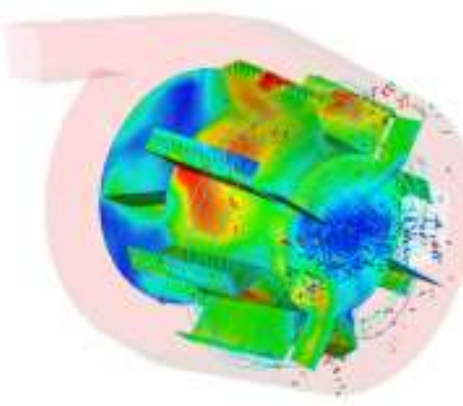

b. $0.06 \mathrm{~s}$

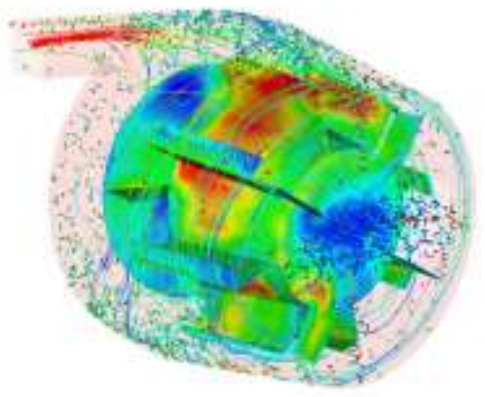

e. $0.50 \mathrm{~s}$

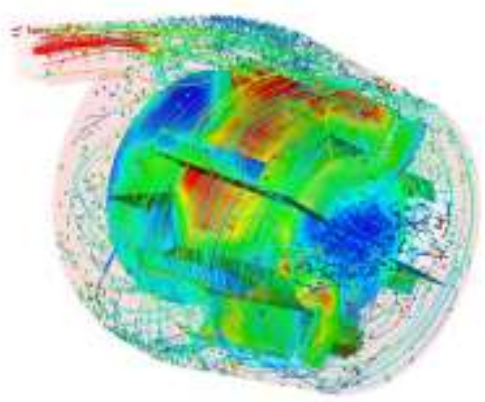

h. $2.00 \mathrm{~s}$

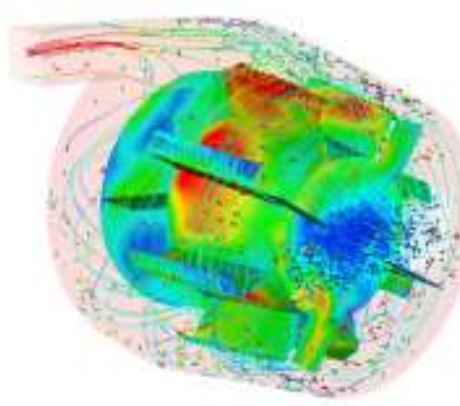

c. $0.13 \mathrm{~s}$

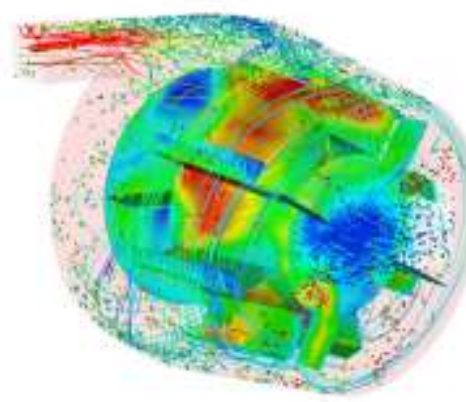

f. $1.00 \mathrm{~s}$

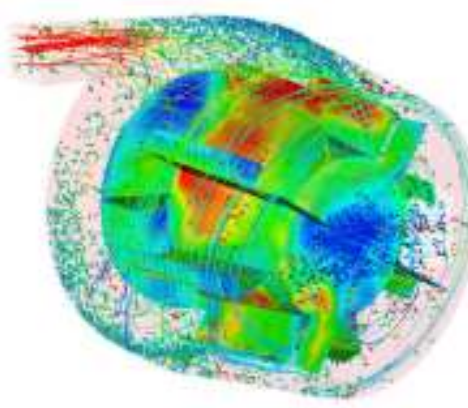

i. $5.00 \mathrm{~s}$

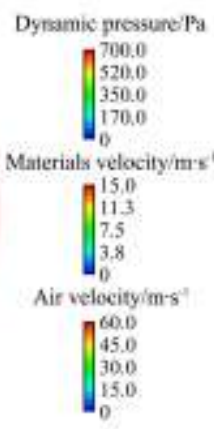

Dynamic pressure $P$.

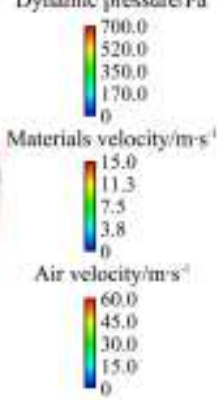

Dynumic pressure $\mathrm{Pa}$

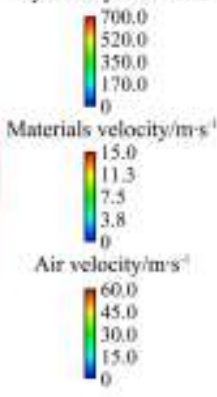

Figure 6 Material transmission process and rule 
Figures 6a-6i show the motion process and rule of materials in the tapered threshing and transmission device when the cylinder rotating speed was $1450 \mathrm{r} / \mathrm{min}$ during time period $t=0.01-5 \mathrm{~s}$. Since CFD-DEM coupling was started under the condition of convergent and stable flow field, when $t=0 \mathrm{~s}$, the EDEM numerical simulation was approximately the working status of the threshing and transmission device. When $t=0.01 \mathrm{~s}$, the material plant produced breeding wheat particles and stalks at inlet air velocity of $12.5 \mathrm{~m} / \mathrm{s}$, initial speed of $0 \mathrm{~m} / \mathrm{s}$, as shown in Figure $6 \mathrm{a}$. When $t=0.06 \mathrm{~s}$, poked by the suction type feeding plate, the materials scattered along the tapered wall of the threshing cylinder, and the cylinder in high-speed revolution sped up the air within the threshing and transmission device (Figures 6c-6d). At this time, the forces on the materials were mainly gravity, pressure gradient force, drag force, spinning lift force, and friction between materials and the cylinder. Afterwards, the materials were at high rotating speed, and reached to the outlet area at last. The amount of materials gradually accumulated at the ascending pipeline. When $t=0.50-1.00 \mathrm{~s}$, the threshed materials accumulated constantly within the device and high-speed air flow was produced at the outlet area of the ascending pipeline to push the materials outside the threshing device rapidly. When $t=1.50-5.00 \mathrm{~s}$ (Figures 6g-6i), the materials in the threshing and transmission device kept stable. After the materials entered into the small area between the L-shaped rasp-bar and plank-tooth and the tapered enclosure wall, then pushed by the high-speed air flow $(11.3-15.0 \mathrm{~m} / \mathrm{s})$, they were transferred to the outlet in the axial direction. As the tapered threshing cylinder kept turning, the dynamic pressure on its upper surface increased from $170 \mathrm{~Pa}$ to $700 \mathrm{~Pa}$ during time period $t=$ $0.01-5.00 \mathrm{~s}$.

\subsection{Average velocity of threshed materials}

At different rotating speeds of the tapered threshing cylinder $(1300 \mathrm{r} / \mathrm{min}, 1450 \mathrm{r} / \mathrm{min}$ and $1600 \mathrm{r} / \mathrm{min}$ ), the variation curves of average velocity of the breeding wheat materials (particles and stalks) with time are shown in Figures $7 \mathrm{a}$ and $7 \mathrm{~b}$. Figure $7 \mathrm{a}$ shows that, within the period $t=0-0.25 \mathrm{~s}$, influenced by the air velocity produced by rotation of the stripping header, the threshed materials entered into the enclosure. The velocity of particles increased with the passage of time. When $t=0.32 \mathrm{~s}$, the average velocity of particles changed abruptly, caused by the collision between particles and the small end face, then the materials were transmitted backward along the cylinder wall under the influence of gravity. When $t=1.50 \mathrm{~s}$, with the increase of diameter of the threshing cylinder, the linear velocity of the materials also increased and particles became loose and expanded, which is convenient for separating and cleaning the materials.

Figure $7 \mathrm{~b}$ shows that, in line with the initial motion status of the particles, within the period $t=0-0.25 \mathrm{~s}$, influenced by the air velocity produced by rotation of the stripping header, wheat stalks entered into the enclosure and their velocity increased with time. When $t=0.32 \mathrm{~s}$, the average velocity of stalks changed abruptly. Caused by the collision between particles and the small end face, then materials were transmitted backward along the cylinder wall under the influence of gravity. When $t=1.00 \mathrm{~s}$, with the increase of diameter of the threshing cylinder, the linear velocity of materials gradually increased to loosen the wheat stalks, which were convenient for later-on separation and cleaning.

The average velocity-time variation curve of the threshed materials (particles and stalks) shows that, although there are differences in average velocity of materials corresponding to three rotating speeds of the threshing cylinder, they are basically consistent in variation tendency. When the rotating speed of the tapered threshing cylinder was $1450 \mathrm{r} / \mathrm{min}$, the fluctuation of average velocity of the threshed materials was less than that under the other two rotating speeds.

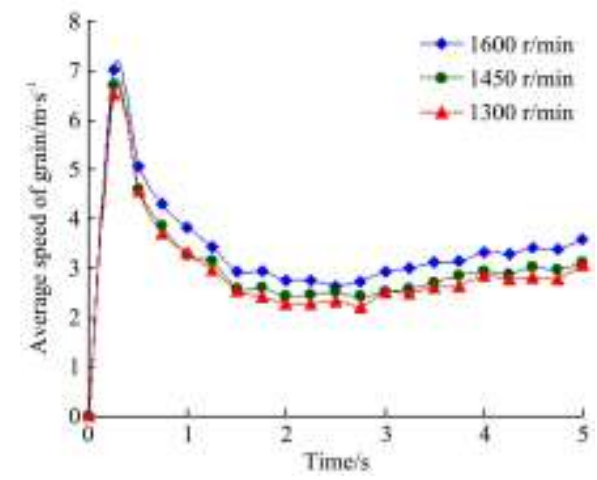

a. Variation curve of average velocity of particles with time

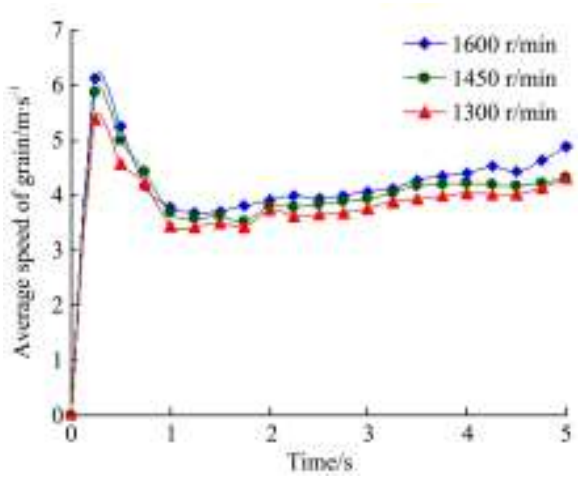

b. Variation curve of average speed of stalks with time

Figure 7 Average velocity of particles and stalks

\subsection{Average displacement of threshed materials}

Under different rotating speeds $(1300 \mathrm{r} / \mathrm{min}, 1450 \mathrm{r} / \mathrm{min}$ and $1600 \mathrm{r} / \mathrm{min}$ ), the variation curve of average different of threshed materials (wheat particles and stalks) with time is shown in Figures $8 \mathrm{a}$ and $8 \mathrm{~b}$.

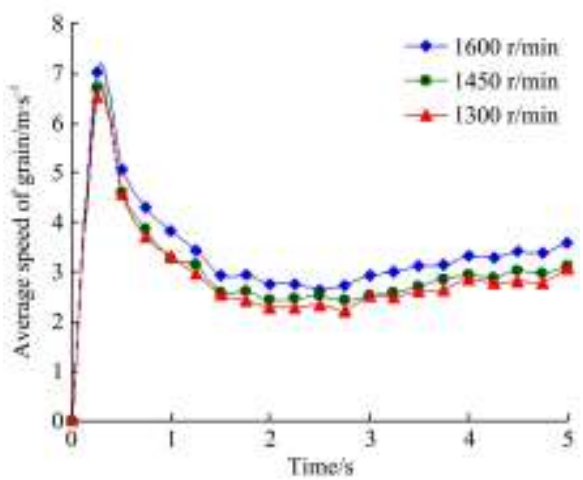

a. Variation curve of average displacement of particles with time

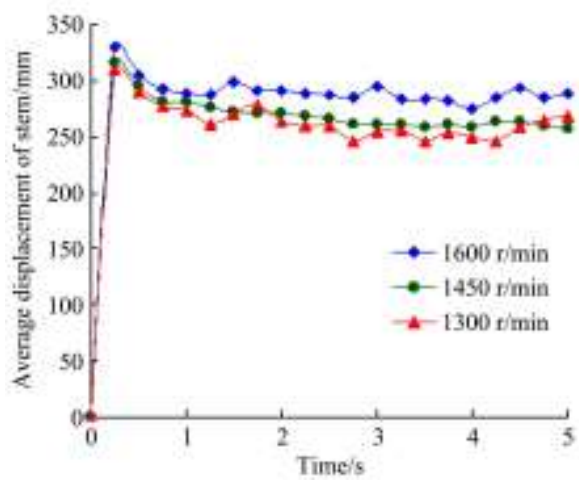

b. Variation curve of average displacement of stalks with passage of time

Figure 8 Average displacements of particles and stalks 
Figure 8 shows that, with the changes in rotating speeds of the tapered cylinder, the changes in displacements of particles and stalks kept relatively stable. Within the period $t=0-0.25 \mathrm{~s}$, the displacement of materials changed at high speed under the influence of rapid air flow at axial direction of the stripping header. When $t=1.00 \mathrm{~s}$, the materials were in stable flowing backward under the influence of the tapered threshing cylinder. The stable flowing of materials was beneficial to alleviating work load of the cleaning system and avoiding retention within the threshing device, and finally ensures the precision of the plot breeding test.

The variation curve of average velocity of the threshed materials (particles and stalks) with time shows that, although there are differences in average displacement of materials corresponding to three rotating speeds of the threshing cylinder, they are basically consistent in variation tendency, the displacement basically remained between $250-330 \mathrm{~mm}$. When the rotating speed of the tapered threshing cylinder was $1450 \mathrm{r} / \mathrm{min}$, the fluctuation of average displacement of the threshed materials was stable compared with that under the other two rotating speeds.

\subsection{Particle retention}

No particle retention within the tapered threshing device is one of the most important performance indicators in plot breeding and harvesting. According to movement trajectory simulation analysis of the material, the region 1 and region 2 were the initial acceptance and final delivery of materials and these regions also had the longest time contacted with the materials. Therefore, region 1 and region 2, which were prone to particle retention under the effects of solid-gas flow in the threshing and transmission device, were analyzed (Figure 9), to find out the influencing factors for material retention.
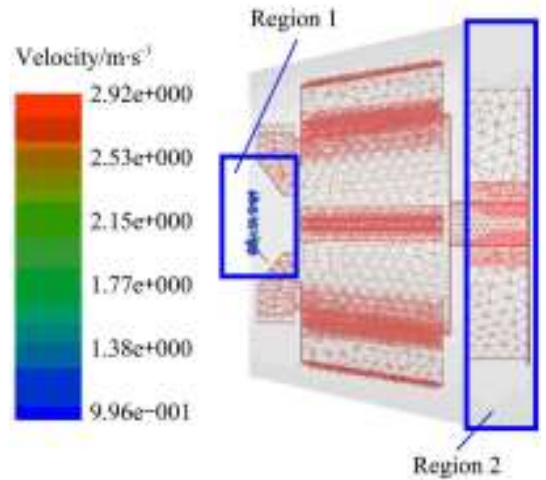

Note: Particle retention emerged in both region 1 and region 2 during the simulation process.

Figure 9 Regions prone to particle retention in the tapered threshing and transmission device

This study above shows that, the materials kept at stable status after $t=1.50 \mathrm{~s}$, the threshed materials began to enter the ascending pipeline stably and orderly. Therefore, under rotating speed of $1450 \mathrm{r} / \mathrm{min}$ of the tapered threshing cylinder, region 1 and region 2 that were prone to particle retention during the stable transmission of materials were observed and analyzed with the software EDEM, as shown in Figure 10.

Figures 10a-10e show that, during the threshing and transmission process, in the region 1 which is formed by small end face and suction type feeding plate, there is a tendency of particle aggregation. However, these particles are in motion state all the time and after the stripping header stopped feeding materials, the particles are transmitted backwards without retention. In region 2 where the winnower is at high rotation speed, the effects of air flow on materials are more prominent.

Most materials were blown out of the threshing and transmission device along the ascending pipeline, while the remaining particles were in a vortex state (Figure 11a) at the rear of the enclosure and accretion under effects of inertia (Figure 11b), showing obvious turbulent flow at the rear of the enclosure.
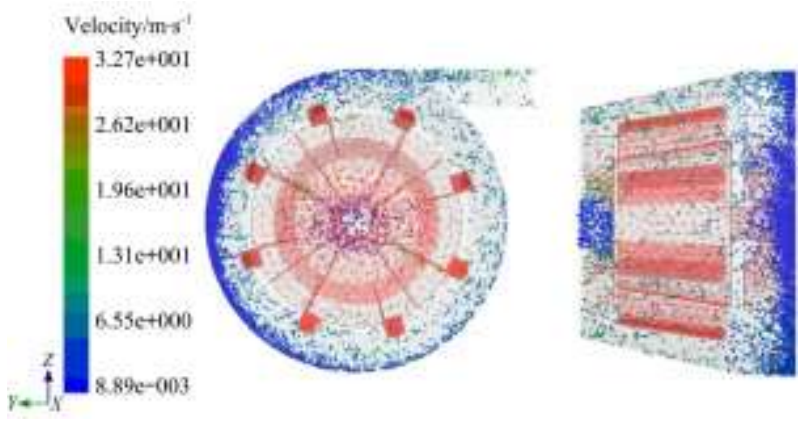

a. $1.00 \mathrm{~s}$
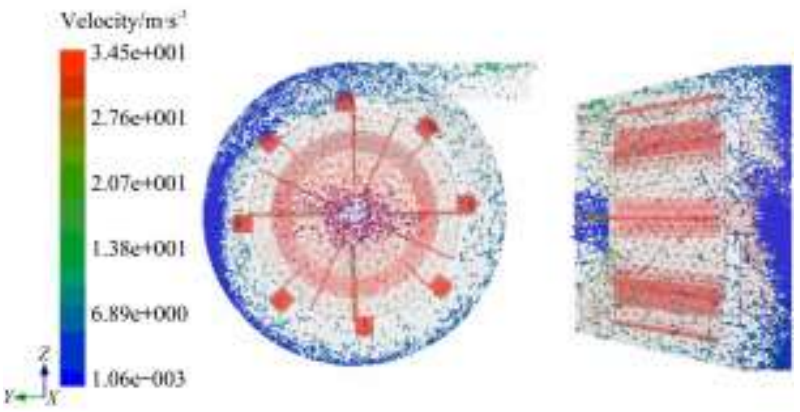

b. $2.00 \mathrm{~s}$
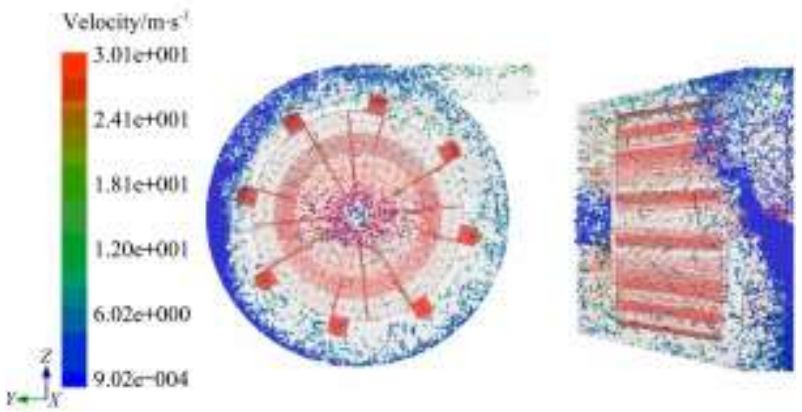

c. $3.00 \mathrm{~s}$
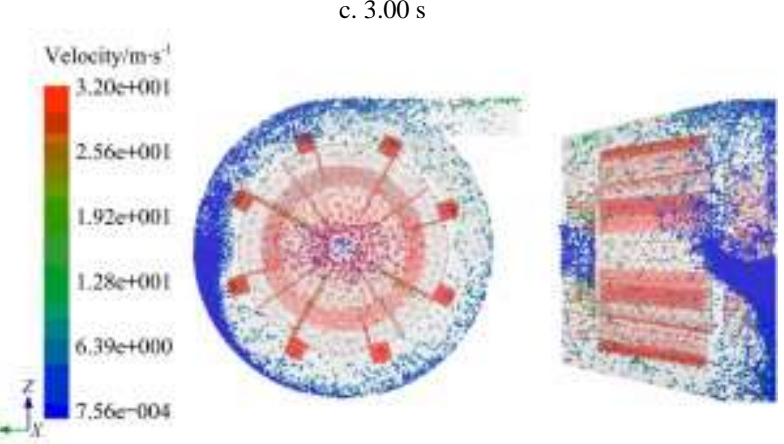

d. $4.00 \mathrm{~s}$
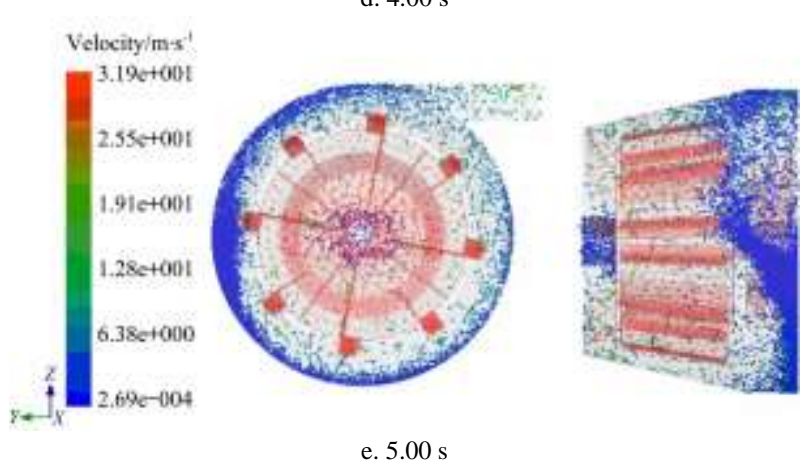

Figure 10 Analysis of regions prone to particle retention in the tapered threshing and transmission device 


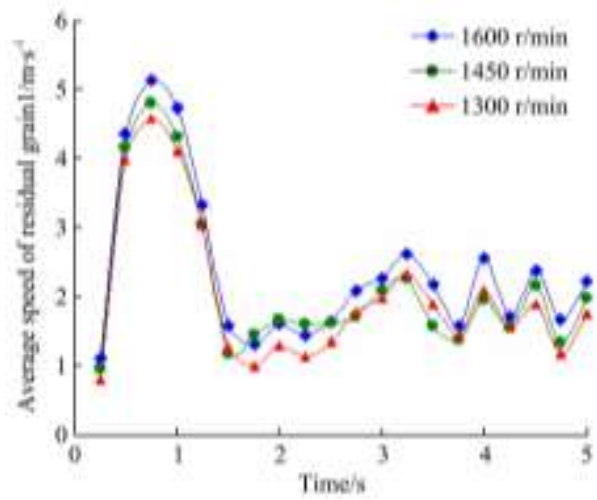

a. Vortex state of particles

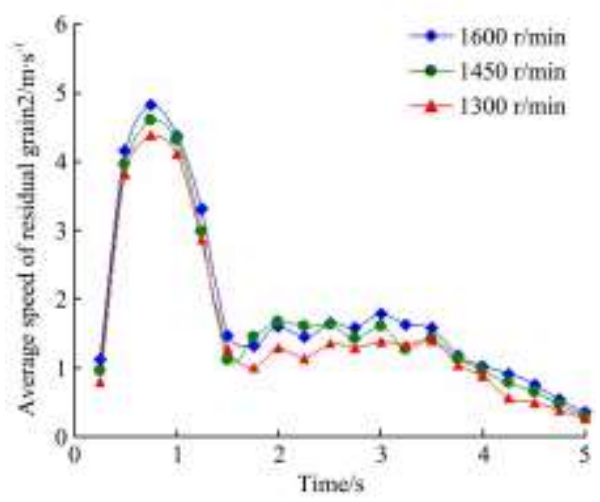

b. Accretion of particles under effects of inertia

Figure 11 Variation curve of velocity of retention particles with time

Figure 11 shows that, during the period of $0-3 \mathrm{~s}$, the velocity of retention particles in the two states went down after an increase and kept stable. After $3 \mathrm{~s}$, some particles aggregated in the left end of the enclosure at an unstable velocity in periodic fluctuation. The particles in turbulent swirling kept a velocity of $1-3 \mathrm{~m} / \mathrm{s}$ and the other particles were thrown onto the enclosure wall under the effects of inertia of the winnower and slid a little under the effects of their own gravity at a velocity of lower than $1 \mathrm{~m} / \mathrm{s}$.

\section{Verification test}

The verification test was carried out at a testbed of a longitudinal-axial plot wheat threshing and transmission device, which was made by Gansu Agricultural University, as shown Figure $12^{[22]}$.

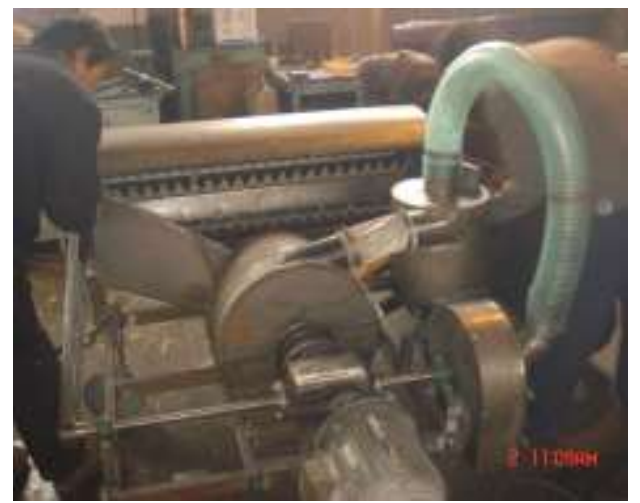

Figure 12 Test bed of grains-threshing performance

Test materials for test are wheat seeds collected from the breeding plot of Gansu Academy of Agricultural Sciences. The variety is Longchun No. 23, with thousand seed mass of $41.2 \mathrm{~g}$, plant height of $650-880 \mathrm{~mm}$, ear length of $80-100 \mathrm{~mm}$ and moisture content of $17.4 \%$. In the test, the air velocity of the threshing header was $12.5 \mathrm{~m} / \mathrm{s}$, feeding amount was $0.3 \mathrm{~kg} / \mathrm{s}$. Driven by the variable frequency motor, the rotating speeds of the tapered cylinder were $1300 \mathrm{r} / \mathrm{min}, 1450 \mathrm{r} / \mathrm{min}$ and $1600 \mathrm{r} / \mathrm{min}$, respectively, and the rotating speed of suction fan was set as $1100 \mathrm{r} / \mathrm{min}$.

Test results showed that, at rotating speeds of 1300-1600 r/min for the tapered threshing cylinder, the grain retention rate in the enclosure was $0-0.13 \%$; comparison between simulation and test results showed that, with the grain retention rate in the enclosure of $0-0.11 \%$ in the simulation, there was only a $0.02 \%$ difference between them. It verified the simulation results of CFD-DEM based on the tapered threshing and transmission device for plot wheat breeding.

\section{Conclusions}

1) After an analysis of the working process of the tapered threshing and transmission device, the fluid governing equations in the device and gas-solid coupling were established; and non-slip contact model and mathematical model of particles, particle model of threshed materials were established based EDEM. The dynamic and static models of calculation domain in the internal flow passage were also established based on FLUENT.

2) After numerical simulation on the motion process of threshed materials in the enclosure of the device based on CFD-DEM, the rule of material transference and distribution and stream field distribution of air flow in the threshing and transmission device were obtained; the variation of velocity and displacement of grains and short stalks with time was obtained, the motion trajectories and motion forms of grains in different types of retention were studied.

3) The variation curve between average velocity and time, average displacement and time of the threshed materials (particles and stalks) shows that, although there are differences in average velocity and displacement of materials corresponding to three rotating speeds of the threshing cylinder, they are basically consistent in variation tendency. When the rotating speed of the tapered threshing cylinder was $1450 \mathrm{r} / \mathrm{min}$, the fluctuation of average velocity and average displacement of the threshed materials was slighter than that under the other two rotating speeds, and resulted in remaining particles at the rear of enclosure in vortex and inertia accretion. The verification test showed that the test results were basically in line with simulation results, when the rotating speed of 1300-1600 $\mathrm{r} / \mathrm{min}$ for the tapered threshing cylinder in the verification test, the particle retention rate in the enclosure was $0-0.13 \%$, while in the simulation the particle retention rate in the enclosure was $0-0.11 \%$, only a $0.02 \%$ difference between them, which proving the feasibility of the threshing and transmission performance of the plot breeding threshing and transmission device through solid-gas coupling method. This research method will be further applied to suggest the ways that can improve the thresher to reduce retention of seeds in the follow-up work.

\section{Acknowledgements}

The authors acknowledge that this work was financially supported by China Agriculture Research System (CARS-14-1-28), Discipline construction fund project of Gansu Agricultural University (GAU-XKJS-2018-189), National Natural Science Foundation of China (Grant No. 51365003). 


\section{[References]}

[1] Zhu M, Chen H J, Li Y L. Investigation and development analysis of seed industry mechanization in China. Transactions of the CSAE, 2015; 31(14): 1-7. (in Chinese)

[2] Shang S Q, Yang R B, Yin Y Y, Guo P Y, Sun Q. Current situation and development trend of mechanization of field experiments. Transactions of the CSAE, 2010; 26(Supp.1): 5-8. (in Chinese)

[3] Fu J, Chen Z, Tian L Q, Han L J, Ren L Q. Review of grain threshing theory and technology. Int J Agric \& Biol Eng, 2018; 11(3): 12-20.

[4] Dai F, Zhao W Y, Han Z S, Li X K, Gao A M, Liu X L. Improvement and experiment on 4GX-100 type wheat harvester for breeding plots. Transactions of the CSAM, 2016; 47(s1): 196-202. (in Chinese)

[5] Tang Z, Li Y M, Xu L Z, Francis K. Modeling and design of a combined transverse and axial flow threshing unit for rice harvesters. Spanish Journal of Agricultural Research, 2014; 12(4): 973-983.

[6] Miu P I. Modeling and simulation of grain threshing and separation in axial threshing units. Part II. Computers and Electronics in Agriculture, 2008; 60(2): 105-109.

[7] Bart L, Bart M, Josse D B, Wouter S, LiDaR sensing to monitor straw output quality of a combine harvester. Computers and Electronics in Agriculture, 2012; 85(1): 40-44.

[8] Chang J G, Liu X B, Ye T, Du M J. Agricultural plot field trial breeding status and development of machinery. Journal of Agricultural Mechanization Research, 2011; 33(2): 238-241. (in Chinese)

[9] Dai F, Zhang F W, Gao A M, Han Z S. Optimization of key operating parameters in 4GX-100 type cropland plot wheat seed combine harvester. Transactions of the CSAE, 2012; 28(Supp.2): 53-58.

[10] Li H C, Li Y M, Gao F, Zhao Z, Xu Li Z. CFD-DEM simulation of material motion in air-and-screen cleaning device. Computers and Electronics in Agriculture, 2012; 88(6): 111-119.

[11] Zhao Z, Li Y M, Liang Z W, Gong Z Q. DEM simulation and physical testing of rice seed impact against a grain loss sensor. Biosystems Engineering, 2013; 116: 410-419.
[12] Liu H X, Guo L F, Fu L L, Tang S F. Study on multi-size seed-metering device for vertical plate soybean precision planter. Int J Agric \& Biol Eng, 2015; 8(1): $1-8$

[13] Boac J M, Ambrose R P K, Casada M E, Maghirang R G, Maier D E Applications of discrete element method in modeling of grain postharvest operations. Food Engineering Reviews, 2014; 6(4): 128-149.

[14] Oldal I, Safranyik F. Extension of silo discharge model based on discrete element method. Journal of Mechanical Science \& Technology, 2015; 29(9): 3789-3796.

[15] Kuang S B, Yu A B, Zou Z S. Computational study of flow regimes in vertical pneumatic conveying. Industrial \& Engineering Chemistry Research, 2009; 48(14): 6846-6858.

[16] He Y, Bayly A E, Hassanpour A L. Coupling CFD-DEM with dynamic meshing: A new approach forfluid-structure interaction in particle-fluid flows. Powder Technology, 2018; 325: 620-631.

[17] Jiang E C, Sun Z F, Pan Z Y, Wang L J. Numerical simulation based on CFD-DEM and experiment of grain moving laws in inertia separation chamber. Transactions of the CSAM, 2014; 45(4): 117-122. (in Chinese)

[18] Liu L Y, Hao S Y, Zhang M, Liu D M, Jia F G, Quan L Z. Numerical simulation and experiment on paddy ventilation resistance based on CFD-DEM. Transactions of the CSAM, 2015; 46(8): 27-32. (in Chinese)

[19] Wang J W, Zhou W Q, Tian L Q, Li S W, Zhang Z. Virtual simulation analysis and verification of seed-filling mechanism for dipper hill-drop precision direct rice seeder. Int J Agric \& Biol Eng, 2017; 10(6): 77-85.

[20] Tong S G, Shen Q, Tang N, Jia Y P, Cong F Y, Gu W. Numerical simulation and optimization experiment of mixed flow field on longitudinal axial flow cleaning device. Transactions of the CSAM, 2016; 47(7): 135-142. (in Chinese)

[21] Chu K W, Wang B. CFD-DEM simulation of the gas-solid flow in a cyclone separator. Chemical Engineering Science, 2011; 66(5): 834-847.

[22] Dai F, Han Z S, Zhang F W, Gao A M, Sun B G. Experiment on longitudinal axial conical cylinder threshing separation unit for plot breeding. Agricultural Research in the Arid Areas, 2012; 30(3): 274-278. (in Chinese) 